Hammer J, Eber E (eds): Paediatric Pulmonary Function Testing.

Prog Respir Res. Basel, Karger, 2005, vol 33, pp 78-91

\title{
Applications and Future Directions of Infant Pulmonary Function Testing
}

\author{
Janet Stocks Sooky Lum \\ Portex Anaesthesia, Intensive Therapy and Respiratory Medicine Unit, Institute of Child Health, \\ London, UK
}

\begin{abstract}
During the past 20 years there has been enormous progress in the field of infant lung function testing, with respect to the range of tests and equipment now available, their applications in research and clinical studies, and the degree of national and international collaboration. The major role for lung function testing in infants remains firmly within the research arena, where it has been extensively used to examine the early determinants of airway function and to investigate underlying pathophysiology and response to therapeutic interventions in a variety of respiratory diseases during early life. During recent years there has been increasing emphasis on developing techniques that can be used in unsedated infants and for those requiring ventilatory support. Future strategies need to encompass a multicenter, multidisciplinary, collaborative approach, with results from infant pulmonary function tests being integrated with those from other disciplines, including imaging, genetics, inflammation and immunology. The aims of this chapter are to (1) provide an overview of the extent to which infant lung function tests have been used in clinical and epidemiological research in the past, (2) describe some of the recently developed techniques that may have increasing application in future years and (3) consider potential future contributions of infant pulmonary function testing in the management of respiratory disease during infancy.
\end{abstract}

\section{Introduction}

As will be evident from the previous chapters, accurate assessment of lung function in infants is no mean undertaking - requiring not only the highest specifications from equipment in terms of frequency response, safety and minimization of both dead space and resistance, but infinite patience and meticulous attention to detail from the operators. The specialized nature of the equipment and time-consuming nature of the tests, which usually require the presence of at least two highly skilled individuals for several hours, means that these tests are far more expensive to perform than those available for older cooperative children. In addition, the information gained from these studies may be limited by lack of appropriate reference data with which to separate the effects of lung disease from those of growth and development, and the need for sedation beyond the neonatal period, which limits study duration, the frequency with which assessments can be undertaken and the acceptability of these tests to many parents.

Despite all these problems, interest in assessing lung function during early life continues to increase. The reasons for this are manifold, but include the fact that it is now realized that much of the burden of respiratory disease in childhood and later life has its origins in infancy and early childhood. Indeed, there is increasing evidence that insults to the developing lung may have lifelong effects, due to the phenomenon of fetal programming, and that remarkable 'tracking' of lung function occurs from infancy throughout life. This has emphasized the need to prevent lung injury both before and after delivery when lung growth is so rapid. In addition, despite recent advances in molecular biology, it is becoming increasingly evident that the effects of new diagnostic and therapeutic advances will still need to be 
evaluated in vivo by employing objective physiological outcome measures in order to better understand the implications of genetics and gene-environment interactions for normal lung growth and development, as well as interpreting the effects of various disease states and response to therapeutic interventions. Furthermore, medical and technological advances have led to increased survival of extremely preterm infants but no reduction in the prevalence of chronic lung disease. This has increased awareness of the need for a better understanding, both of lung growth and development, and the effect of different ventilatory strategies, in order to minimize lung injury during this critical period.

The need to meet this increased demand and overcome at least some of the barriers to obtaining accurate and relevant information in this age group was recognized by the formation of the joint American Thoracic Society/European Respiratory Society (ATS/ERS) Task Force. This international task force has been extremely active in this field for the past 10 years, organizing regular workshops and postgraduate courses, and publishing a textbook and series of manuscripts to provide guidelines for developing more standardized equipment and techniques. Nevertheless, as will be discussed below, the clinical usefulness of these tests within individual infants remains far more limited than in older subjects.

The aims of this chapter are to (1) provide an overview of the extent to which infant lung function tests have been used in clinical and epidemiological research in the past, (2) describe briefly some of the lesser-known recently developed techniques that may have increasing application in future years and (3) consider potential future contributions of infant pulmonary function tests (PFTs) in the management of respiratory disease during infancy, including what would be required before infant PFTs could play a significant role in the clinical management of individual infants; in other words, what we know, what we need to know and what the future challenges are.

\section{Previous Applications of Infant PFTs}

\section{Introduction}

The major role for lung function testing in infants remains firmly within the research arena, where it has been extensively used to examine the early determinants of airway function and to investigate underlying pathophysiology and response to therapeutic interventions in a variety of respiratory diseases during early life. An impressive array of tests is now available for use in infants, allowing accurate assessment of lung volumes, respiratory mechanics and control of breathing by those with the necessary skills and patience to apply them. The most commonly used tests have been those of forced expiration, passive respiratory mechanics and measurements of lung volume by inert gas dilution or whole body plethysmography. Application of these tests in clinical research studies has furthered our knowledge with respect to (1) the early determinants of airway function, including the adverse effect of preterm delivery, intrauterine growth retardation and pre- and postnatal exposure to tobacco smoke, (2) natural history of diseases such as cystic fibrosis (CF), chronic lung disease and wheezing illnesses (which affect up to $40 \%$ infants in first year of life), (3) bronchial responsiveness in early life and (4) lung growth and development following neonatal lung disease.

Some of the more recent applications and findings are summarized below.

\section{Applications of Infant Lung Function Testing in Epidemiological Research}

Early Determinants of Respiratory Function

Numerous studies have shown that the sex of an infant has a marked effect on airway function, as reflected by the lower maximal expiratory flows observed in boys compared with girls at any given height both during infancy [1-5] and later childhood. This may contribute to the increased prevalence of wheezing in boys at all ages to puberty. Although this male disadvantage disappears after puberty, the increased perinatal mortality and respiratory morbidity among boys suggest a broader vulnerability to early life events in young males. It is therefore important to use sexspecific reference data when predicting 'normal ranges' of airway function [6], to avoid underestimating the degree of any impairment in girls, or overestimating it in boys. Although less is known about the impact of ethnic group on lung function during early life, both nasal and airway resistance have been shown to be lower in Afro-Caribbean than Caucasian infants. Significant differences in breathing pattern and forced expired flows between these two groups have also been reported in those delivered prematurely $[2,7]$ suggesting either that the respiratory system is more mature, or that lung and airway function are relatively enhanced in Afro-Caribbean infants delivered prematurely.

During the last few years, there has been increasing evidence of the adverse effects of maternal smoking on infant lung function $[5,8-10]$. This effect is apparent at least 7 weeks prior to the expected date of delivery [7], and is independent of any postnatal exposure, as demonstrated by studies that have assessed lung function in healthy 
infants prior to discharge from the neonatal unit $[7,11,12]$. A recent review of the literature found that, while there is no convincing evidence from studies in human infants that smoking during pregnancy is associated with increased airway responsiveness at birth, many studies have demonstrated a reduction in baseline forced expiratory flows (by an average of around 20\%), as well as increases in both airway and total resistance [13]. In addition, there is substantial evidence regarding the adverse effect of maternal smoking during pregnancy on postnatal control of breathing, particularly with respect to a blunted response to hypoxia, hypercapnia and arousal stimuli $[14,15]$. In infants born to atopic mothers, exhaled nitric oxide levels are increased shortly after birth in those exposed to maternal smoking, while the reverse appears to be true amongst those delivered to nonatopic mothers [16]. This underlines the complex interactions of maternal and environmental factors on the development of airway disease. While maternal smoking during pregnancy remains the most significant source of early life exposure to tobacco products and is likely to be largely responsible for diminished airway function in the first few years of life, continuing postnatal tobacco smoke exposure from either parent will increase the risk of respiratory infections, wheezing illnesses and diminished lung function throughout childhood [13]. The effect of parental smoking has an equally adverse effect on infants with lung disease [17], thereby necessitating careful recording of such exposures if results from either clinical or research studies are to be interpreted correctly.

A family history of atopy, particularly maternal asthma, has also been shown to be associated with diminished airway function and increased airway responsiveness during the first years of life $[1,4,8,9,18-21]$. Despite increasing emphasis on the potential effect of intrauterine growth retardation on subsequent health throughout life [22-24], relatively little was known until recently about the impact of being born 'small for gestational age' on lung function during infancy. During the past few years, a study has been undertaken in which over 200 healthy infants were recruited to address this issue. After adjusting for all known confounders, including age, sex and current body size, timed forced expiratory volumes from raised lung volume were found to be significantly lower in infants born small for gestational age than in appropriately grown controls, with a similar tendency for forced expired flows [19], these changes persisting throughout the first year of life [20]. This study also highlighted the complex interactions between birth weight, socioeconomic status, family history of atopy, parental smoking and airway function in infants, and emphasized the need for large numbers of infants to be recruited to studies such as these if meaningful conclusions are to be reached.

Infant Lung Function as a Predictor of Subsequent Respiratory Morbidity?

The Tucson Children Respiratory Study was the first longitudinal assessment of the natural history of asthma that included infant lung function tests [25]. Over 1,200 children were enrolled at birth. Eight hundred of these were still participating at 13 years of age [26], although only $10 \%$ of these subjects had had lung function measured in the first few months of life. This study was the first to provide evidence that diminished airway function precedes wheezing illness, in that the tidal breathing ratio $\left(t_{\text {PTEF }}: t_{E}\right)$ was significantly lower in boys (though not in girls) who subsequently wheezed with a lower respiratory illness (LRI) in the first year of life. Although there was no significant difference in $\mathrm{V}^{\prime}{ }_{\operatorname{maxFRC}}$ between those who did and did not wheeze when follow-up was limited to the first year of life, subsequent follow-up revealed a diminution of $\mathrm{V}^{\prime}{ }_{\max }{ }_{\text {RRC }}$ shortly after birth in those who wheezed during the first year and who had had at least one additional wheezing LRI by 3 years of age [26]. Similar findings were reported from the Boston study [10] (who also used $\mathrm{V}^{\prime}{ }_{\operatorname{maxFRC}}$ as an outcome measure) and in the London study, which found elevated premorbid values of airway resistance in those who subsequently wheezed in the first year [9]. By contrast, the Perth longitudinal study suggested that reduced airway function in early life was associated with persistent wheeze at 11 years but not with transient wheeze [27]. Discrepancies between results may reflect differences in techniques, methods of statistical analysis, population and environment as well as the fact that, although a large number of children may be recruited to longitudinal studies during infancy, the number in whom repeated lung function measures can be made on all test occasions may be relatively small due to the inherent difficulties in conducting such studies. Nevertheless, despite the wide range of techniques used, all of these studies have provided evidence of diminished premorbid lung function shortly after birth amongst those with subsequent wheezing illness.

While one of the major aims of these epidemiological studies, namely to predict which infants who wheeze are likely to progress to asthma in later life, has not yet been realized, considerable knowledge has been gleaned regarding the range of different wheezing phenotypes. It is now generally acknowledged that those with very early onset of wheeze (first year of life), whose mothers smoke and in whom there is no family history of asthma or atopy have a relatively low risk for asthma. By contrast, those in whom 
onset of wheeze occurs later and/or in the absence of any significant exposure to pre- or postnatal tobacco smoke, where there is a maternal history of asthma, persistent personal atopy (initially to food and later to inhaled allergens) and an increased bronchial responsiveness (with or without diminished flows) in infancy, will have a much higher risk for subsequent asthma [26].

Serial measurements of lung function from cohort studies have also revealed considerable tracking of lung function (i.e. those with the lowest levels of airway function initially tend to retain this position throughout life). This has been demonstrated in healthy term [20] and preterm [28] infants, in infants and young children with CF $[29,30]$ and between infancy and school age in those with bronchopulmonary dysplasia [31]. There is thus increasing evidence that some infants are born more susceptible to respiratory problems and that lung function during later life may be largely determined by factors occurring before or shortly after birth.

\section{Problems in Assessing Lung Function \\ in Infants with Respiratory Disease}

Despite numerous attempts to monitor changes in lung function as a means of identifying early onset of pulmonary disease during the first year of life, the natural course of pulmonary involvement in infants with respiratory disorders remains relatively poorly understood [32, 33]. Problems encountered include: (1) contraindication of sedation in the presence of acute respiratory disease [34], (2) difficulties in repeating measurements frequently enough, (3) difficulties in distinguishing the effects of disease from those of growth and development, in the absence of a control group or appropriate reference data, (4) confounding of measurements by developmental changes in chest wall compliance and/or the dominance of the upper airways when measuring airway or total respiratory resistance [35], and (5) increased within-subject variability of measurements among infants with respiratory disease [36, 37].

Further difficulties in interpreting results from clinical studies - whether in an individual infant or within the context of a research study - arise from the fact that many of the assumptions underlying measurements of lung volumes and mechanics, such as rapid equilibration of pressures throughout the respiratory system (as required for accurate measures of lung volumes by plethysmography or passive respiratory mechanics using airway occlusion techniques), or the presence of a single time constant during passive lung emptying (single breath technique), may be violated in the presence of severe airway obstruction. Similarly, the choice of method used to assess lung volumes may be critical, with any gas trapped behind closed or slowly ventilating areas secondary to airway obstruction being detectable by plethysmographic but not gas dilution techniques.

\section{Applications of Infant Lung Function Testing in Clinical Research Studies}

Despite these problems there is a vast literature describing the application of infant lung function tests in clinical research: the rapid thoracoabdominal compression technique for measuring $\mathrm{V}^{\prime}{ }_{\operatorname{maxFRC}}$ being the most commonly used method for assessing airway function in this age group.

\section{Baseline Lung Function in Infants with}

\section{Respiratory Disease}

$\mathrm{V}^{\prime}{ }_{\text {maxFRC }}$ has been shown to be lower in infants with recurrent wheeze [26], bronchiolitis [38], tracheomalacia [39] and those with history of life-threatening events [40]. Application of these tests in infants with CF has been summarized recently [41, 42]. Most studies have reported diminished lung and airway function in symptomatic infants [42-47]. It has recently been shown that airway function is reduced at an early stage in infants with $\mathrm{CF}$, even in the absence of clinically recognized LRI [48] and that this does not catch up during infancy and early childhood [29]. These findings have important potential implications for early interventions in CF. While several reports have suggested that the raised volume technique may be a more sensitive means of discriminating changes in lung function in infants with respiratory disease than either tidal breathing parameters [49] or $\mathrm{V}_{\text {maxFRC }}^{\prime}[17,50]$, it should be remembered that this technique is more complex to apply and that guidelines to standardize data collection and analysis are only just beginning to emerge $[51,52]$.

\section{Response to Therapeutic Interventions}

Several studies have been designed wherein results from lung function tests have been used to assess response to therapeutic interventions, such as antibiotic treatment or administration of corticosteroids [43, 44, 47]. The varying conclusions from such studies may be partially attributable to the heterogeneous nature of both disease severity and individual response to therapy among the infants studied, but may also reflect the relatively small number of subjects within each of these studies, with inevitable consequences with respect to potential sampling bias and power of study.

Bronchial Responsiveness

One of the most extensively studied clinical research areas in which infant lung function tests have been applied 
is that of bronchial responsiveness using both bronchial challenge and bronchodilation [36, 53-59]. There is currently no standardized approach to performing either type of intervention, with respect to agent used, dosage, mode of delivery, outcome measures or methods of analyzing and reporting results. This has resulted in considerable difficulties when attempting to elucidate age-related changes in airway responsiveness during early life [60, 61].

Measurements of resistance and forced expiratory flows have been the two most commonly used methods for assessing change in airway function during such studies, although recent work has suggested that assessment of tissue mechanics may also be valuable [54]. Although resistance is a direct assessment of airway caliber, airway or pulmonary resistance may be dominated by the caliber of extrathoracic nose breathing in infants. Forced expiratory flows should provide a better reflection of changes in intrathoracic airway caliber, but are themselves highly dependent on lung volume and airway tone, both of which may change in response to the intervention, resulting in an underestimation of the degree of airway responsiveness. Interpretation of these studies is further complicated by the lack of information regarding intra-subject, between-test repeatability on the same occasion [36, $53,62]$.

Despite the generally poor response to bronchodilators in early life, there is convincing evidence that the airways are fully innervated and capable of responding to a range of challenges during both fetal and early postnatal life (56, 63). The effectiveness of bronchodilators in wheezy infants remains controversial $[59,64]$, reflecting the fact that, in many infants who wheeze, the reduction in baseline airway function is not due to reversible bronchoconstriction, but transient conditions associated with diminished airway patency [65].

Applications during and following Intensive Care

Numerous studies have attempted to use parameters derived from infant lung function tests to assess the effects of preterm delivery, neonatal lung disease and ventilatory support $[15,66-75]$. The most commonly used approaches in recent years have been assessments of passive respiratory mechanics and lung volumes $[66,67$, $76]$. The only volume that has been routinely measured in infants during mechanical ventilation has been that at end expiration with or without positive end-expiratory pressure [67, 70, 77-79], although determination of lung volumes over an extended volume range using the negative deflation technique has also been described in specialized centers $[80,81]$.
Specific difficulties in undertaking and interpreting measurements of infant lung function during intensive care (over and above those encountered when assessing spontaneously breathing infants) have been reviewed previously [74, 76, 82, 83] and arise from factors including the following:

1. Relative invasiveness of these techniques in clinically unstable infants.

2. Insensitivity of the test to changes in respiratory mechanics within individuals due, for example, to the relative magnitude of resistance of the tracheal tube [84, 85] or the underlying pathophysiology.

3. Inaccuracies in displayed values of tidal volume [86].

4. Confounding of results due to interactions between the ventilator and spontaneous breathing activity [76].

5. Leaks around the tracheal tube [87], which may invalidate attempts to assess lung function in intubated infants and yet remain difficult to eliminate due to widespread use of uncuffed tubes in this age group. Recent evidence suggesting that, at least beyond the neonatal period, cuffed tubes may not be associated with an increased risk of upper airway trauma and may facilitate ventilatory management in those with severe respiratory problems $[88,89]$ may reduce such problems in the future.

6. Heterogeneous nature of the population with respect to maturity, body size and clinical severity.

7. Multitude of possible treatment modalities that infants may be exposed to.

8. Fact that results are frequently corrected for body size simply by expressing data as a ratio (per kilogram body weight or, even worse, per centimeter body length). Unless it can be shown that there is a linear relationship between the selected lung function parameter and body size, with no intercept on extrapolation (which is unlikely to be the case following preterm delivery) the use of such ratios may severely distort comparisons between infants of differing body size and maturity, and hence the effect of any disease process, its resolution or treatment. In such circumstances the use of multivariate analysis is likely to be the preferred option, but demands substantial sample size to achieve adequate power of study.

Although several studies have suggested that measurements of respiratory mechanics may be predictive of subsequent bronchopulmonary dysplasia (BPD) [72, 90, 91], this was not confirmed in a randomized controlled study of mechanically ventilated neonates who were assigned to conventional management with or without daily assessments of lung mechanics [92]. Post hoc 
analysis did, however, show that survivors in whom such measurements had been performed were ventilated for a significantly shorter period (median 3 vs. 5 days) compared with controls. The authors also calculated that a much larger sample size would be required to achieve adequate power of study for their original study aim.

It is becoming increasingly evident that preterm delivery, even in the absence of any initial respiratory disease may have an adverse effect on subsequent lung growth and development [93-95] which persists and may even worsen throughout the first years of life [28, 96, 97]. Most studies in infants with BPD or chronic lung disease of infancy have suggested that lung volumes are low early in infancy but subsequently become normal or elevated [66]. This has been attributed to the fact that, over time, pulmonary fibrosis may become less important relative to airway disease and that lung volumes may, therefore, increase disproportionately with growth. Studies of infants with BPD/chronic lung disease of infancy have also reported reduced compliance $[90,91,98]$ and increased resistance $[90,91]$ during the first year of life. As mentioned above, some caution may be required when interpreting these results, depending on the methods used to express pulmonary function in relation to body size. Lung function tests have also been used as objective outcome measures to assess the effect of different types of ventilatory support, including extra-corporeal membrane oxygenation and high frequency oscillation, during the neonatal period on subsequent lung growth and development [71, 97, 99-103].

\section{New Approaches to Assessing Respiratory Function in Infants}

The expanding role of infant lung function testing in both clinical and research studies has been accompanied in recent years by the development of new approaches to assessing lung function during early life as well as further modification of well-established techniques. While their use is not yet widespread and commercially available equipment is scarce, several of these techniques have considerable future potential for clinical measurements and are therefore reviewed briefly below.

Beyond the neonatal period, wheezing disorders of either a transient or persistent pattern tend to dominate most of the respiratory problems encountered in infants and young children, as reflected by the emphasis placed on assessment of airway function in this age group. Nevertheless there is increasing awareness that airway resistance and forced expired flows are determined not only by the caliber of the airways, but by the compliance of the airway wall and recoil of the surrounding parenchyma, leading to the search for suitable parameters that will reflect these characteristics and hence improve interpretation of results.

Recent modifications of the long-established forced oscillation technique, in which respiratory impedance $\left(Z_{\mathrm{rs}}\right)$ is measured by superimposing small amplitude pressure oscillations on the respiratory system and measuring the resultant oscillatory flow [104], have met with remarkable success in this area. One of the advantages of this technique is that it can be applied during spontaneous tidal breathing and requires no special maneuvers, making it potentially applicable in young and unsedated infants. Depending on the frequency of the applied pressure wave, the resultant impedance will contain different mechanical information. The response to very slow pressure oscillations $(<2 \mathrm{~Hz})$, during what is commonly referred to as the low-frequency forced oscillation technique (LFOT), allows the noninvasive partitioning of lung function into airway and tissue parameters $[73,105,106]$. By contrast, at very high frequencies, using a technique that has come to be known as the 'high frequency interrupter technique' or HIT, the information derived is primarily related to airway wall mechanics, which is particularly important in wheezing disorders [107]. Impedance measurements should only be used if measured signals are of high quality since large errors and misinterpretation of data can occur with poor quality signals. The key advantage of both the HIT and LFOT is that they can be applied during relatively brief interruptions to the normal breathing pattern during spontaneous quiet sleep, even in rapidly breathing infants. The major limitation of the LFOT is the requirement for apnea during the external oscillations, since the small amplitude oscillatory signal does not contain sufficient power to suppress the influence of the higher harmonics of spontaneous breathing. This is usually achieved by administering several augmented breaths $(2 \mathrm{kPa})$ and holding the lung at raised lung volume to invoke the Hering-Breuer reflex and hence a respiratory pause before applying the oscillations. Development of a monitoring technique that provides information on tissue mechanics is of particular interest for studies in preterm infants, where parenchymal disease is a major component of acute respiratory illness, and in whom failure of alveolarization has been targeted as a major feature of subsequent chronic lung disease [66]. In addition to monitoring lung growth and development, the LFOT has the potential for estimating the mechanically optimal lung volume in intubated infants during highfrequency oscillatory ventilation, as recently shown in the preterm lung model [108]. 
Although initially described many years ago, the multiple breath inert gas washout technique has only been used intermittently in infants and young children [94, 109], possibly reflecting the complexity of data analysis and the lack of commercially available equipment and software. During recent years, technological advances combined with increasing awareness that indices of ventilation inhomogeneity, such as the lung clearance index (cumulative expired volume/FRC), provide a sensitive measure of small airway disease $[110,111]$ and that conventional measures of airway function may not detect early changes in peripheral airway function until lung disease is well-established [111] have led to a resurgence of interest in this field. The multiple breath gas mixing technique has great potential as measurements are performed during spontaneous breathing, making it applicable to subjects of all ages, including unsedated infants. A further advantage of this approach is that, in health, gas mixing efficiency remains remarkably stable throughout life, enabling the effects of disease to be distinguished from those of growth and development with far greater confidence than when dealing with most parameters of lung function which are highly dependent on age and body size. Recent work has demonstrated that the multiple breath inert gas washout technique is a far more sensitive method of detecting early changes in lung function amongst infants and children with CF than more conventional measures of forced expired flows and volumes [111, 112]. Recent development and ongoing validation of the ultrasonic flowmeter may mean that, in the future, reliable measurements will be available not only in unsedated preterm and newborn infants, but on the intensive care unit (ICU) [74, 113].

Recent refinements of the noninvasive imaging method of electrical impedance tomography to assess spatial distribution of ventilation and its application in both ventilated and spontaneously breathing infants also bode well for the future use of this method, both during and following pediatric intensive care. Serial measurements using electrical impedance tomography in ventilated infants were able to identify the redistribution of lung ventilation and changes in the magnitude of regional ventilation in response to alterations in ventilator settings, surfactant instillation and changes in posture $[114,115]$. Provided further adaptations of hardware and software can be implemented to improve practical handling and facilitate stable and undisturbed measurements in the ICU, this noninvasive method could become a useful bedside monitoring tool of regional lung ventilation in critically ill infants, with important implications for optimizing lung volume and minimizing lung injury.
A relatively neglected area of investigation that has received more attention recently has been that relating to chest wall mechanics and the respiratory muscles [116]. Dysfunction of the respiratory muscles may not only result in disease, but render an infant unable to compensate for the effects of such disease, with the underlying cause of ventilatory failure in approximately $50 \%$ preterm infants being attributed to respiratory muscle failure. Knowledge relating to the strength of the respiratory muscles may be potentially useful in a number of clinical situations, including whether or not to wean an infant from the ventilator and when assessing recovery from acute infections [116]. Methods of assessing respiratory muscle strength include the determination of maximal inspired and expired pressures during respiratory efforts against brief airway occlusions [117], although the marked within- and between-subject variability of this measure may limit its clinical usefulness. Furthermore, simple assessment of respiratory muscle strength does not reflect either endurance or susceptibility to fatigue. Work is currently being undertaken to evaluate the discriminative ability of alternative indices, such as the tension time index of the respiratory muscles. The latter has several advantages in that it is completely noninvasive, does not require placement of gastric or esophageal pressure transducers and assesses muscle fatigue in all the respiratory muscles - not simply the diaphragm. Its potential usefulness has, however, still to be evaluated in infants [116].

Esophageal manometry was once commonplace during assessments of lung function in infants [118], but nowadays its use has generally been replaced by the assessment of passive respiratory mechanics using one of the occlusion techniques [119], except in ventilated or preterm infants who may already be receiving regular nasogastric feeds. In situations where esophageal manometry is still required, the use of esophageal balloons and water-filled catheters has largely been replaced by catheter tip transducers [120].

The need to assess not only respiratory mechanics but gas exchange and control of breathing when assessing infants with respiratory disease, particularly in those delivered prematurely or requiring ventilatory support, has been recognized in several recent publications $[14,15,66$, 121-125]. Similarly, despite recognized difficulties in accurately interpreting measures of exhaled nitric oxide as a noninvasive marker of airway inflammation in infants, due to the influence of nasal breathing and the marked flow dependency of such measures, there have been some interesting reports describing their potential utility in both clinical and epidemiological studies, which warrant further investigation [16, 126-128]. Although further refinement 
and standardization of the technique are required, bedside equipment for evaluation of such markers is now available for use in infants.

Requirements for noninvasive methods of assessing lung function during natural sleep or during prolonged periods of monitoring have resulted in persistent efforts to analyze tidal breathing parameters, whether derived from changes in flow and volume at the airway opening or from body surface measurements [129]. Following initial reports regarding the potential predictive value of the time to peak expiratory flow as a ratio of total expiratory time $\left(t_{\text {PTEF }}: t_{E}\right)$ [25], a plethora of publications was followed by a degree of disillusionment as it became obvious that the prime role of such indices would be in large epidemiological studies of newborn infants, rather than any clinical application within individuals [130-134]. Nevertheless the potential for such noninvasive methods has inspired several groups to continue the search for improved methods of analyzing and reporting such data [135]. Frey et al. [136] have proposed that tidal flow is an integrated output of the neural respiratory oscillator in the brainstem, which in turn reflects the processing of interacting chemo- and stretch receptor feedback mechanisms as well as passive mechanics of the lung and chest wall. They subsequently quantified the harmonic content of the tidal flow wave form, arguing that such complex neuromechanical respiratory control would be better characterized by considering the entire periodic tidal flow waveform rather than simple indices derived from a limited number of points, as is the case when simply reporting $t_{\text {PTEF }}: t_{E}$. Not only does this approach have exciting potential in terms of increasing and integrating our understanding of respiratory mechanics and control of breathing during early life, but it has been recently adapted for use in the clinical scenario. Habib et al. [137] recently extended this approach by analyzing the tidal flow waveform derived from respiratory inductance plethysmography in spontaneously breathing preterm infants and reported that the harmonic content of tidal flow in such infants is characterized by a power law functional form power spectrum. They were also able to demonstrate that essentially equivalent flow spectra and corresponding shape indices could be attained from direct measurements at the mouth or indirect distant flows measured at the chest wall. Providing this can be confirmed by other groups, this is an important finding, given the desirable nonintrusive nature of body surface measurements, which can potentially: (1) avoid errors arising either from leaks around the face mask or from the adverse effects of apparatus dead space and resistance when recording breathing patterns at the airway opening in very small infants [138, 139], (2) facilitate measurements over longer time periods and (3) allow delivery of treatments such as nasal continuous positive airway pressure and inspired oxygen during the measurement period.

The potential limitations of deriving either qualitative or quantitative assessments of flow and volume from body surface recordings, particularly in the presence of any marked asynchrony between chest wall and abdominal movements $[140,141]$ must, however, be borne in mind when attempting such measurements.

\section{What Is the Potential Contribution of Infant PFTs to Future Management of Respiratory Disease during Early Life?}

Infant lung function tests could potentially be used for early diagnosis and monitoring of lung disease, assessment of the therapeutic interventions and evaluation of disease outcome. While there is little doubt about the potential value of infant lung function tests as a means of providing objective outcome measures in clinical or epidemiological research studies, their potential usefulness with respect to influencing clinical management within an individual infant remains far more debatable, as reviewed in several recent publications [32, 33, 74, 142-145].

Lung function tests at any age are rarely performed for diagnostic purposes, but rather to monitor the nature and severity of respiratory disease or to assess the response to treatment [146]. The clinical usefulness of any technique depends not only on its ability to measure parameters that are relevant to the underlying pathophysiology and to discriminate between health and disease, but on within-subject repeatability both within and between test occasions. As discussed above, whilst highly reproducible measurements of lung function can be made in infants during the same test occasion, little is yet known about the 'between-test repeatability'. For spontaneously breathing infants, this lack of data relates primarily to factors such as difficulties of repeat sedation, and the time constraints of working parents to bring infants for repeat measurements at intervals less than 4-6 monthly. By contrast, the ability to assess repeatability in the intubated inpatient is limited more by factors such as clinical instability, or problems in maintaining stable measurement conditions between such repeat measures. Considerable effort will be required to collect data in this field if we are to distinguish what constitutes a clinically significant change within an individual infant as a result of disease progression or response to treatment.

Similar problems arise with respect to distinguishing the effects of disease from those of growth and development 
[147]. The need for sedation limits the numbers of healthy infants that can be studied during spontaneous breathing, while relatively few truly 'normal' infants are anesthetized or ventilated and hence available to provide representative values under these particular circumstances. Some limited attempts have been made to establish reference data for intubated infants and children but far more work will be required in this field if newly developed techniques are to be fully utilized.

Recent international collaborative efforts have led to the publication of sex-specific reference data for $\mathrm{V}^{\prime}{ }_{\operatorname{maxFRC}}$ during infancy [6]. The development of more standardized equipment and techniques for infant lung function testing will hopefully encourage and facilitate similar initiatives in the future, so that appropriate regression equations, which can take into account important determinants such as length, body weight, age, maturity, sex and ethnic group, can be developed. It is important to realize that much of the older published literature, frequently quoted when interpreting data from infants with respiratory disease, may no longer be appropriate due to the technological advances in both equipment and methodology that have occurred during recent years [148]. It is therefore imperative that, as with measurements in older children [149, 150], infant lung function results are interpreted with great caution unless the operators can verify the validity of their chosen reference data.

If appropriate equipment was to be miniaturized and/or incorporated into the ventilatory circuit, so that continuous online monitoring of appropriate parameters could be undertaken, the major area in which infant lung function tests could influence clinical management in the future probably lies in the neonatal and pediatric ICU. Given the current rate of technological development, this is certainly feasible, but will demand a major commitment by all concerned, plus the recognition that most of the tests used in the past are too complex and/or too insensitive to provide the clinician with reliable and relevant information with which to guide treatment. Techniques that should be targeted include those that measure absolute, and changes in, lung volume, tissue mechanics, distribution of ventilation, gas mixing efficiency, oxygen consumption, control of breathing and respiratory muscle function, with results being carefully integrated with other relevant outputs, including blood gases, ventilator settings and direct or noninvasive markers of inflammation. Many of these measurements will require not only the presence of leak-free tracheal tubes in infants who are intubated, but a much improved knowledge of respiratory physiology amongst pediatricians and intensivists if the information provided is to be utilized in a meaningful fashion. Interpretation of results will also depend on knowledge of growth and development of the lung, particularly after extremely preterm delivery, and more sophisticated adjustment for body size than simply dividing by weight or length as is all too common at present. The latter is particularly critical in the presence of somatic growth retardation.

Other areas where there may be a real role for infant lung function testing are with respect to longitudinal measurements from birth and throughout the preschool years in high risk groups - such as those with persistent wheezing, $\mathrm{CF}$ and chronic lung disease. The potential prognostic value of such tests within individual subjects is as yet unknown, since it is only during the last few years that more routine assessments of lung function have been possible throughout the preschool years [151-154], but such studies are currently being undertaken. Interpretation of such data will require similar longitudinal measurements to be performed among healthy children from birth to school age.

Within an individual infant, the clinical usefulness of any lung function test will always be enhanced if serial measures can be undertaken rather than a single assessment, and if the choice of test is based on the question to be answered, clinical reasoning and a knowledge of the suspected underlying pathophysiology, rather than simply on the equipment that happens to be available in any given center. Thus if bronchial responsiveness is to be assessed using either a bronchodilator or bronchial challenge, the selected test should: (1) have low intrasubject variability (which should ideally be assessed on the same occasion, and under similar measurement conditions), (2) be sensitive to the physiological changes that are likely to occur during the challenge, and (3) remain valid in the presence of alterations of airway mechanics.

Similarly, while assessment of respiratory compliance may be relevant in a newborn infant receiving surfactant (provided it is combined with measures of lung volume), it is unlikely to provide much insight into the effects of treatment in a wheezy toddler. The choice of technique will also very much depend on the setting, with many of the currently available tests such as the raised volume technique requiring highly trained staff and sophisticated equipment.

It is generally agreed that no single lung function test will ever provide the answer, and that a combination of tests is required, the results of which should be interpreted in the light of other information regarding present clinical status and prior medical and social history. Given the marked influence of factors such as preterm delivery, intrauterine growth retardation, sex and maternal smoking during pregnancy, it is particularly important to take a careful 
history from the parents when performing such tests. Accurate measures of weight and length (using a calibrated stadiometer and 2 trained individuals [34]) is also essential as is taking into account the potential influence of failure to thrive on the results obtained. Thus in a child with CF whose weight is below the 3rd centile for age, expression of lung volume per kilogram body weight will tend to overestimate the presence of any hyperinflation, while the reverse will be true in an obese young child with recurrent wheezing.

The largest groups of infants with respiratory problems are those with wheezing disorders, infants with chronic lung disease or respiratory failure during the neonatal period, who may suffer from combined obstructive and restrictive lung disease, and those with chronic progressive diseases such as CF. If more information were available regarding within-subject, within- and between-occasion repeatability of selected measurements together with appropriate reference data, any of these infants could potentially benefit from serial measurements to assess disease progression and possibly to determine appropriate therapeutic strategies. This possibility would be enhanced if more sensitive techniques were developed - including assessments of alveolar surface area, pulmonary capillary blood flow and tissue mechanics for those recovering for chronic lung disease. By contrast, while respiratory infections are common in infancy, assessments of lung function are unlikely to have any impact on their management.

In a recent review, Godfrey et al. [144] concluded that the only infants in whom assessments of lung function should be performed for purely clinical reasons were: (1) those who present with unexplained tachypnea, hypoxia, cough or respiratory distress in whom a definitive diagnosis is not apparent from physical examination and other investigations, (2) infants with severe, continuous, chronic obstructive lung disease who do not respond to an adequate clinical trial of combined corticosteroid and bronchodilator therapy or (3) infants with known respiratory disease of uncertain severity in whom there is a need to justify management decisions.

Whether or not these criteria will be extended in the future, if improved noninvasive methods of studying unsedated infants or those receiving ventilatory support are developed, remains to be seen.

It is not yet known whether serial assessment of lung function in infants with CF, chronic lung disease or persistent wheeze will alter their clinical management. To some extent this will depend on the prognostic value of assessments of lung function during the first year of life, information that will only become available once serial lung function measurements from diagnosis to school age become available.

\section{Conclusions}

During the past 20 years there have been major advances in the field of infant lung function testing, with respect to the quality of equipment now available, the range of tests applicable in this age range and the degree of national and international collaboration and standardization. Challenging areas in which infant lung function tests could usefully be employed in the future include: (1) elucidation of the mechanisms by which insults to the developing lung contribute to respiratory disease, (2) identification of which of the many infants who wheeze in the first year of life go on to develop asthma, (3) determination of the most beneficial treatments for various lung diseases, (4) preservation of lung function in infants with progressive lung diseases such as CF by detection of, and appropriate interventions for, early changes in lung function, (5) identification of factors that contribute to the development of chronic lung disease of prematurity so that alternative, improved strategies of both antenatal and postnatal management can be developed, (6) continuous on-line, noninvasive monitoring of appropriate respiratory parameters in ventilated infants for individual optimization of ventilatory support, and (7) longitudinal studies of lung growth and development in health and disease from birth to school age, taking advantage of recent developments in the field of preschool testing.

Future strategies need to encompass a multicenter, multidisciplinary, collaborative approach, whereby there are increasing links between structure and function (particularly with respect to some of the exciting developments in the field of noninvasive imaging) and between physiology, epidemiology, genetics, inflammation and immunology. Ultimately the aim should be to further develop and validate infant respiratory function tests so that they can be used as objective and reliable outcome measures both in individual infants and in multicenter clinical trials, thereby strengthening the scientific basis for the prevention and treatment of respiratory disease in early life, as well as providing insights into the mysteries of the developing lung. 


\section{References}

1 Clarke JR, Salmon B, Silverman M: Bronchial responsiveness in the neonatal period as a risk factor for wheezing in infancy. Am J Respir Crit Care Med 1995;151:1434-1440.

2 Stocks J, Henschen M, Hoo A-F, Costeloe $\mathrm{KC}$, Dezateux CA: Influence of ethnicity and gender on airway function in preterm infants. Am J Respir Crit Care Med 1997;156: 1855-1862.

3 Jones M, Castile R, Davis S, Kisling J, Filbrun D, Flucke R, Goldstein A, Emsley C, Ambrosius W, Tepper RS: Forced expiratory flows and volumes in infants. Am J Respir Crit Care Med 2000;161:353-359.

4 Lum S, Hoo AF, Dezateux C, Goetz I, Wade A, DeRooy L, Costeloe K, Stocks J: The association between birthweight, sex, and airway function in infants of nonsmoking mothers. Am J Respir Crit Care Med 2001; 164:2078-2084.

5 Young S, Sherrill DL, Arnott J, Diepeveen D, Le Souëf PN, Landau LI: Parental factors affecting respiratory function during the first year of life. Pediatr Pulmonol 2000;29: 331-340.

6 Hoo AF, Dezateux C, Hanrahan J, Cole TJ, Tepper R, Stocks J: Sex-specific prediction equations for $\mathrm{V}^{\prime}$ maxFRC in infancy: $\mathrm{A}$ multi-center collaborative study. Am J Respir Crit Care Med 2002;165:1084-1092.

7 Hoo A-F, Henschen M, Dezateux CA, Costeloe KC, Stocks J: Respiratory function among preterm infants whose mothers smoked during pregnancy. Am J Respir Crit Care Med 1998;158:700-705.

8 Dezateux C, Stocks J, Dundas I, Fletcher ME: Impaired airway function and wheezing in infancy. The influence of maternal smoking and a genetic predisposition to asthma. Am J Respir Crit Care Med 1999;159: 403-410.

9 Dezateux C, Stocks J, Wade AM, Dundas I, Fletcher ME: Airway function at one year: Association with premorbid airway function, wheezing and maternal smoking. Thorax 2001;56:680-686.

10 Tager IB, Hanrahan JP, Tosteson TD, Castile RG, Brown RW, Weiss ST, Speizer FE: Lung function, pre- and post-natal smoke exposure, and wheezing in the first year of life. Am Rev Respir Dis 1993;147:811-817.

11 Lodrup Carlsen KC, Jaakkola JJK, Nafstad $\mathrm{P}$, Carlsen KH: In utero exposure to cigarette smoking influences lung function at birth. Eur Respir J 1997;10:1774-1779.

12 Stick SM, Burton PR, Gurrin L, Sly PD: Effects of maternal smoking during pregnancy and a family history of asthma on respiratory function in newborn infants. Lancet 1996;348:1060-1064.

13 Stocks J, Dezateux C: The effect of parental smoking on lung function and development during infancy. Respirology 2003;8:266285.

14 Chang AB, Wilson SJ, Masters IB, Yuill M, Williams J, Williams G, Hubbard $M$ : Altered arousal response in infants exposed to cigarette smoke. Arch Dis Child 2003;88: 30-33.
15 Sawnani H, Jackson T, Murphy T, Beckerman $\mathrm{R}$, Simakajornboon N: The effect of maternal smoking on respiratory and arousal patterns in preterm infants during sleep. Am J Respir Crit Care Med 2004;169:733-738.

16 Frey U, Kuehni C, Roiha H, Cernelc M, Reinmann B, Wildhaber JH, et al: Maternal atopic disease modifies effects of prenatal risk factors on exhaled nitric oxide in infants. Am J Respir Crit Care Med 2004;170:260-265.

17 Ranganathan SC, Bush A, Dezateux C, Carr SB, Hoo AF, Lum S, Madge S, Price J, Stroobant J, Wade A, Wallis C, Wyatt H: Relative ability of full and partial forced expiratory maneuvers to identify diminished airway function in infants with cystic fibrosis. Am J Respir Crit Care Med 2002;166:1350 1357.

18 Sheikh S, Goldsmith LJ, Howell L, Parry L, Eid $\mathrm{N}$ : Comparison of lung function in infants exposed to maternal smoking and in infants with a family history of asthma. Chest 1999;116:52-58.

19 Dezateux C, Lum S, Hoo AF, Hawdon J, Costeloe K, Stocks J: Low birth weight for gestation and airway function in infancy: Exploring the fetal origins hypothesis. Thorax 2004;59:60-66.

20 Hoo A-F, Stocks J, Lum S, Wade AM, Castle RA, Costeloe KL, et al: Development of lung function in early life: Influence of birthweight in infants of non-smokers. Am J Respir Crit Care Med, in press.

21 Murray CS, Pipis SD, McArdle EC, Lowe LA, Custovic A, Woodcock A: Lung function at one month of age as a risk factor for infant respiratory symptoms in a high risk population. Thorax 2002;57:388-392.

22 Godfrey KM, Barker DJ: Fetal programming and adult health. Public Health Nutr 2001;4: 611-624.

23 Osmond C, Barker DJ: Fetal, infant, and childhood growth are predictors of coronary heart disease, diabetes, and hypertension in adult men and women. Environ Health Perspect 2000;108(suppl 3):545-553.

24 Stein CE, Kumaran K, Fall CHD, Shaheen SO, Osmond C, Barker DJP: Relation of fetal growth to adult lung function in South India. Thorax 1997;52:895-899.

25 Martinez FD, Morgan WJ, Wright AL, Holberg CJ, Taussig LM: Diminished lung function as a predisposing factor for wheezing respiratory illness in infants. N Engl J Med 1988;319:1112-1117.

26 Taussig LM, Wright AL, Holberg CJ, Halonen M, Morgan WJ, Martinez FD: Tucson Children's Respiratory Study: 1980 to present. J Allergy Clin Immunol 2003;111:661-675.

27 Turner SW, Palmer LJ, Rye PJ, Gibson NA, Judge PK, Cox M, Young S, Goldblatt J, Landau LI, Le Souef PN: The relationship between infant airway function, childhood airway responsiveness, and asthma. Am J Respir Crit Care Med 2004;169:921-927.

28 Hoo AF, Dezateux C, Henschen M, Costeloe $\mathrm{K}$, Stocks J: Development of airway function in infancy after preterm delivery. J Pediatr 2002;141:652-658.
29 Ranganathan SC, Stocks J, Dezateux C, Bush A, Wade A, Carr S, Castle R, Dinwiddie R, Hoo AF, Lum S, Price J, Stroobant J: The evolution of airway function in early childhood following clinical diagnosis of cystic fibrosis. Am J Respir Crit Care Med 2004; 169:928-933.

30 Marostica PJ, Weist AD, Eigen H, Angelicchio C, Christoph K, Savage J, Grant D, Tepper RS: Spirometry in 3- to 6-year-old children with cystic fibrosis. Am J Respir Crit Care Med 2002;166:67-71.

31 Filippone M, Sartor M, Zacchello F, Baraldi E: Flow limitation in infants with bronchopulmonary dysplasia and respiratory function at school age. Lancet 2003;361: 753-754.

32 Dezateux CA, Wade AM, Schmalisch G, Landau L: Maximizing effective research in infant respiratory function; in Stocks $\mathrm{J}$, Sly PD, Tepper RS, Morgan WJ (eds): Infan Respiratory Function Testing. New York, Wiley, 1996, pp 521-550.

33 Frey U: Clinical applications of infant lung function testing: Does it contribute to clinical decision making? Paediatr Respir Rev 2001; 2:126-130.

34 Gaultier C, Fletcher M, Beardsmore C, Motoyama E, Stocks J: Measurement conditions; in Stocks J, Sly PD, Tepper RS, Morgan WJ (eds): Infant Respiratory Function Testing. New York, Wiley, 1996, pp 29-44.

35 Stocks J: Developmental physiology and methodology. Am J Respir Crit Care Med 1995;151:S15-S17.

36 Lagerstrand L, Ingemansson M, Bergstrom SE, Lidberg K, Hedlin G: Tidal volume forced expiration in asthmatic infants: Reproducibility and reversibility tests. Respiration 2002;69:389-396.

37 Malmberg LP, Pelkonen A, Hakulinen A, Hero M, Pohjavuori M, Skytta J, Turpeinen $\mathrm{M}$ : Intraindividual variability of infant whole-body plethysmographic measurements: Effects of age and disease. Pediatr Pulmonol 1999;28:356-362.

38 Modl M, Eber E, Weinhandl E, Gruber W, Zach MS: Assessment of bronchodilator responsiveness in infants with bronchiolitis. A comparison of the tital and the raised volume rapid thoracoabdominal compression technique. Am J Respir Crit Care Med 2000; 161:763-768.

39 Davis S, Jones M, Kisling J, Angelicchio C, Tepper RS: Effect of continuous positive airway pressure on forced expiratory flows in infants with tracheomalacia. Am J Respir Crit Care Med 1998;158:148-152.

40 Hartmann H, Seidenberg J, Noyes JP, O’Brien L, Poets CF, Samuels MP, Southall DP: Small airway patency in infants with apparent lifethreatening events. Eur J Pediatr 1998;157: 71-74

41 Gappa M, Ranganathan S, Stocks J: Lung function testing in infants with cystic fibrosis: Lessons from the past and future directions. Pediatr Pulmonol 2001;32:228-245. 
42 Gappa M: The infant with cystic fibrosis: Lung function. Paediatr Respir Rev 2004; 5(suppl 1):S361-S364.

43 Beardsmore CS, Thompson JR, Williams A, Mcardle EK, Gregory GA, Weaver LT, Simpson H: Pulmonary function in infants with cystic fibrosis: The effect of antibiotic treatment. Arch Dis Child 1994;71:133-137.

44 Clayton RG Sr, Diaz CE, Bashir NS, Panitch HB, Schidlow DV, Allen JL: Pulmonary function in hospitalized infants and toddlers with cystic fibrosis. J Pediatr 1998;132:405-408.

45 Dakin CJ, Numa AH, Wang H, Morton JR, Vertzyas CC, Henry RL: Inflammation, infection, and pulmonary function in infants and young children with cystic fibrosis. Am J Respir Crit Care Med 2002;165:904-910.

46 Nixon GM, Armstrong DS, Carzino R, Carlin JB, Olinsky A, Robertson CF, Grimwood K: Early airway infection, inflammation, and lung function in cystic fibrosis. Arch Dis Child 2002;87:306-311

47 Tepper RS, Eigen H, Stevens J, Angelicchio C, Kisling J, Ambrosius W, Heilman D: Lower respiratory illness in infants and young children with cystic fibrosis: Evaluation of treatment with intravenous hydrocortisone. Pediatr Pulmonol 1997;24:48-51.

48 Ranganathan S, Dezateux CA, Bush A, Carr SB, Castle R, Madge SL, Price JF, Stroobant J, Wade AM, Wallis CE, Stocks J: Airway function in infants newly diagnosed with cystic fibrosis. Lancet 2001;358:19641965.

49 Ranganathan SC, Goetz I, Hoo AF, Lum S, Castle R, Stocks J: Assessment of tidal breathing parameters in infants with cystic fibrosis. Eur Respir J 2003;22:761-766.

50 Jones MH, Howard J, Davis S, Kisling J, Tepper RS: Sensitivity of spirometric measurements to detect airway obstruction in infants. Am J Respir Crit Care Med 2003; 167:1283-1286.

51 ATS-ERS consensus statement: Raised volume forced expirations in infants: Guidelines for current practice. Am J Respir Crit Care Med, in press.

52 Lum S, Hulskamp G, Hoo AF, Ljungberg H, Stocks J: Effect of the raised lung volume technique on subsequent measures of $V^{\prime}$ maxFRC in infants. Pediatr Pulmonol 2004;38:146-154.

53 Goldstein AB, Castile RG, Davis SD, Filbrun DA, Flucke RL, McCoy KS, Tepper RS: Bronchodilator responsiveness in normal infants and young children. Am J Respir Crit Care Med 2001;164:447-454

54 Hall GL, Hantos Z, Wildhaber JH, Petak F, Sly PD: Methacholine responsiveness in infants assessed with low frequency forced oscillation and forced expiration techniques. Thorax 2001;56:42-47.

55 Hayden MJ, Devadason SG, Sly PD, Wildhaber JH, Le Souëf PN: Methacholine responsiveness using the raised volume forced expiration technique in infants. Am J Respir Crit Care Med 1997;155:1670-1675.

56 Weist A, Williams T, Kisling J, Clem C, Tepper RS: Volume history and effect on airway reactivity in infants and adults. J Appl Physiol 2002;93:1069-1074.
57 Palmer LJ, Rye PJ, Gibson NA, Burton PR, Landau LI, Le Souëf PN: Airway responsiveness in early infancy predicts asthma, lung function, and respiratory symptoms by school age. Am J Respir Crit Care Med 2001; 163:37-42.

58 Young S, Arnott J, O’Keeffe PT, Le Souëf PN, Landau LI: The association between early life lung function and wheezing during the first 2 years of life. Eur Respir J 2000;15:151-157.

59 Modl M, Eber E, Weinhandl E, Gruber W, Zach MS: Assessment of bronchodilator responsiveness in infants with bronchiolitis. A comparison of the tidal and the raised volume rapid thoracoabdominal compression technique. Am J Respir Crit Care Med 2000; 161:763-768.

60 Collis GG, Cole CH, Le Souëf PN: Dilution of nebulised aerosols by air entrainment in children. Lancet 1990;336:341-343.

61 Le Souëf PN, Sears MR, Sherrill D: The effect of size and age of subject on airway responsiveness in children. Am J Respir Crit Care Med 1995;152:576-579.

62 Lum S, Stocks J: Reproducibility and reversibility of tidal forced expirations. Respiration 2003;70:556.

63 Hislop A: Fetal and postnatal anatomical development; in Greenough A, Roberton NRC, Milner AD (eds): Neonatal Respiratory Disorders. London, Arnold, 1995, pp 3-12.

64 Stick SM, Arnott J, Turner DJ, Young S, Landau LI, Le Souëf PN: Bronchial responsiveness and lung function in recurrently wheezy infants. Am Rev Respir Dis 1991; 144:1012-1015.

65 Hofhuis W, van der Wiel EC, Tiddens HA, Brinkhorst G, Holland WP, de Jongste JC, Merkus PJ: Bronchodilation in infants with malacia or recurrent wheeze. Arch Dis Child 2003;88:246-249.

66 Allen J, Zwerdling R, Ehrenkranz R, Gaultier C, Geggel R, Greenough A, Kleinman R, Klijanowicz A, Martinez F, Ozdemir A, Panitch HB, Nickerson B: Statement on the care of the child with chronic lung disease of infancy and childhood. Am J Respir Crit Care Med 2003;168:356-396.

67 Bhat RY, Leipala JA, Singh NR, Rafferty GF, Hannam S, Greenough A: Effect of posture on oxygenation, lung volume, and respiratory mechanics in premature infants studied before discharge. Pediatrics 2003; 112:29-32.

68 Choukroun ML, Tayara N, Fayon M, Demarquez JL: Early respiratory system mechanics and the prediction of chronic lung disease in ventilated preterm neonates requiring surfactant treatment. Biol Neonate 2003; 83:30-35.

69 Dimitriou G, Cheeseman P, Greenough A: Lung volume and the response to high volume strategy, high frequency oscillation. Acta Paediatr 2004;93:613-617.

70 Dinger J, Topfer A, Schaller P, Schwarze R: Functional residual capacity and compliance of the respiratory system after surfactant treatment in premature infants with severe respiratory distress syndrome. Eur J Pediatr 2002;161:485-490.
71 Dobyns EL, Griebel J, Kinsella JP, Abman SH, Accurso FJ: Infant lung function after inhaled nitric oxide therapy for persistent pulmonary hypertension of the newborn. Pediatr Pulmonol 1999;28:24-30.

72 Kavvadia V, Greenough A, Dimitriou G: Early prediction of chronic oxygen dependency by lung function test results. Pediatr Pulmonol 2000;29:19-26.

73 Petak F, Babik B, Asztalos T, Hall GL, Deak ZI, Sly PD, Hantos Z: Airway and tissue mechanics in anesthetized paralyzed children. Pediatr Pulmonol 2003:35:169-176.

74 Schibler A, Frey U: Role of lung function testing in the management of mechanically ventilated infants. Arch Dis Child Fetal Neonatal Ed 2002;87:F7-F10.

75 Seddon PC, Davis GM: Validity of esophageal pressure measurements with positive end-expiratory pressure in preterm infants. Pediatr Pulmonol 2003;36:216-222.

76 Sly PD, Lanteri C, Nicolai T: Measurement of respiratory function in the intensive care unit; in Stocks J, Sly PD, Tepper RS, Morgan WJ (eds): Infant Respiratory Function Testing. New York, Wiley, 1996, pp 445-484.

77 Dinger J, Topfer A, Schaller P, Schwarze R: Effect of positive end expiratory pressure on functional residual capacity and compliance in surfactant-treated preterm infants. J Perinat Med 2001;29:137-143.

78 McEvoy C, Bowling S, Williamson K, Stewart M, Durand M: Functional residual capacity and passive compliance measurements after antenatal steroid therapy in preterm infants. Pediatr Pulmonol 2001;31:425-430.

79 Schibler A, Henning R: Positive end-expiratory pressure and ventilation inhomogeneity in mechanically ventilated children. Pediatr Crit Care Med 2002;3:124-128.

80 Hammer J, Numa A, Newth CJ: Total lung capacity by $\mathrm{N}_{2}$ washout from high and low lung volumes in ventilated infants and children. Am J Respir Crit Care Med 1998;158: 526-531.

81 Hammer J, Patel N, Newth CJ: Effect of forced deflation maneuvers upon measurements of respiratory mechanics in ventilated infants. Intensive Care Med 2003;29:2004-2008.

82 Hjalmarson O: Lung function testing Useless in ventilated newborns? Eur J Pediatr 1994;153:S22-S26.

83 Stocks J: Infant respiratory function testing: Is it worth all the effort? Paediatr Anaesth 2004:14:537-540.

84 Keidan I, Fine GF, Kagawa T, Schneck FX, Motoyama EK: Work of breathing during spontaneous ventilation in anesthetized children: A comparative study among the face mask, laryngeal mask airway and endotracheal tube. Anesth Analg 2000;91:1381-1388.

85 Manczur T, Greenough A, Nicholson GP, Rafferty GF: Resistance of pediatric and neonatal endotracheal tubes: Influence of flow rate, size, and shape. Crit Care Med 2000;28:1595-1598.

86 Castle RA, Dunne CJ, Mok Q, Wade AM, Stocks J: Accuracy of displayed values of tidal volume in the pediatric intensive care unit. Crit Care Med 2002;30:2566-2574. 
87 Main E, Castle R, Stocks J, James IG, Hatch DJ: The influence of endotracheal tube leak on the assessment of respiratory function in ventilated children. Intensive Care Med 2001;27:1788-1797.

88 James I: Cuffed tubes in children. Paediatr Anaesth 2001;11:259-263.

89 Newth CJ, Rachman B, Patel N, Hammer J: The use of cuffed versus uncuffed endotracheal tubes in pediatric intensive care. J Pediatr 2004; 144:333-337.

90 Lui K, Lloyd J, Ang E, Rynn M, Gupta JM: Early changes in respiratory compliance and resistance during the development of bronchopulmonary dysplasia in the era of surfactant therapy. Pediatr Pulmonol 2000; 30:282-290.

91 Tortorolo L, Vento G, Matassa PG, Zecca E, Romagnoli C: Early changes of pulmonary mechanics to predict the severity of bronchopulmonary dysplasia in ventilated preterm infants. J Matern Fetal Neonatal Med 2002; 12:332-337.

92 Stenson BJ, Glover RM, Wilkie RA, Laing IA, Tarnow-Mordi WO: Randomised controlled trial of respiratory system compliance measurements in mechanically ventilated neonates. Arch Dis Child 1998;78:F15-F19.

93 Gappa M, Stocks J, Merkus P: Lung growth and development after preterm birth: Further evidence. Am J Respir Crit Care Med 2003; 168:399.

94 Hjalmarson O, Sandberg K: Abnormal lung function in healthy preterm infants. Am J Respir Crit Care Med 2002;165: 83-87.

95 Jobe AH: An unknown: Lung growth and development after very preterm birth. Am J Respir Crit Care Med 2002;166: 1529-1530.

96 Talmaciu I, Ren CL, Kolb SM, Hickey E, Panitch HB: Pulmonary function in technology-dependent children 2 years and older with bronchopulmonary dysplasia. Pediatr Pulmonol 2002;33:181-188.

97 Hofhuis W, Huysman MW, van der Wiel EC, Holland WP, Hop WC, Brinkhorst G, de Jongste JC, Merkus PJ: Worsening of $\mathrm{V}^{\prime}$ maxFRC in infants with chronic lung disease in the first year of life: A more favorable outcome after high-frequency oscillation ventilation. Am J Respir Crit Care Med 2002; 166:1539-1543.

98 Baraldi E, Filippone M, Trevisanuto D, Zanardo V, Zacchello F: Pulmonary function until two years of life in infants with bronchopulmonary dysplasia. Am J Respir Crit Care Med 1997;155:149-155.

99 Beardsmore C, Dundas I, Poole K, Enock K, Stocks J: Respiratory function in survivors of the United Kingdom Extracorporeal Membrane Oxygenation Trial. Am J Respir Crit Care Med 2000;161:1129-1135.

100 Dundas I, Beardsmore CS, Wellman T, Stocks J: A Collaborative study of infant respiratory function testing. Eur Respir J 1998; 12:944-953.

101 Donn SM, Sinha SK: Can mechanical ventilation strategies reduce chronic lung disease? Semin Neonatol 2003;8:441-448.
102 Habib RH, Pyon KH, Courtney SE: Optimal high-frequency oscillatory ventilation settings by nonlinear lung mechanics analysis. Am J Respir Crit Care Med 2002;166:950-953.

103 Thomas MR, Rafferty GF, Limb ES, Peacock JL, Calvert SA, Marlow N, Milner AD, Greenough A: Pulmonary function at followup of very preterm infants from the United Kingdom oscillation study. Am J Respir Crit Care Med 2004;169:868-872.

104 Oostveen E, MacLeod D, Lorino H, Farre R, Hantos Z, Desager K, Marchal F: The forced oscillation technique in clinical practice: Methodology, recommendations and future developments. Eur Respir J 2003;22: 1026-1041.

105 Hall GL, Hantos Z, Sly PD: Altered respiratory tissue mechanics in asymptomatic wheezy infants. Am J Respir Crit Care Med 2001;164:1387-1391.

106 Pillow JJ, Hall GL, Willett KE, Jobe AH, Hantos Z, Sly PD: Effects of gestation and antenatal steroid on airway and tissue mechanics in newborn lambs. Am J Respir Crit Care Med 2001;163:1158-1163.

107 Frey U, Makkonen K, Wellman T, Beardsmore C, Silverman M: Alterations in airway wall properties in infants with a history of wheezing disorders. Am J Respir Crit Care Med 2000;161:1825-1829.

108 Pillow JJ, Sly PD, Hantos Z: Monitoring of lung volume recruitment and derecruitment using oscillatory mechanics during highfrequency oscillatory ventilation in the preterm lamb. Pediatr Crit Care Med 2004; 5:172-180.

109 Shao H, Sandberg K, Hjalmarson O Impaired gas mixing and low lung volume in preterm infants with mild chronic lung disease. Pediatr Res 1998;43:536-541.

110 Coates AL: Classical respiratory physiology Gone the way of the dinosaurs? Do we need a jurassic park? Pediatr Pulmonol 2000;30:1-2.

111 Gustafsson PM, Aurora P, Lindblad A Evaluation of ventilation maldistribution as an early indicator of lung disease in children with cystic fibrosis. Eur Respir J 2003;22: 972-979.

112 Ljungberg H, Hulskamp G, Hoo AF, Lum S, Pillow JJ, Aurora P, Gustafsson P, Stocks J: Abnormal lung clearance index (LCI) is more common than reduced $\mathrm{FEV}_{0.5}$ in infants with CF. Am J Respir Crit Care Med 2003; 167:A41

113 Schibler A, Hall GL, Businger F, Reinmann B, Wildhaber JH, Cernelc M, Frey U: Measurement of lung volume and ventilation distribution with an ultrasonic flow meter in healthy infants. Eur Respir J 2002;20 912-918.

114 Frerichs I, Schiffmann H, Oehler R, Dudykevych T, Hahn G, Hinz J, Hellige G: Distribution of lung ventilation in spontaneously breathing neonates lying in different body positions. Intensive Care Med 2003; 29:787-794

115 Frerichs I: Electrical impedance tomography (EIT) in applications related to lung and ventilation: A review of experimental and clinical activities. Physiol Meas 2000;21:R1-21.
116 Traeger N, Panitch HB: Tests of respiratory muscle strength in neonates. Neo Rev 2004;5:e208-e214.

117 Manczur TI, Greenough A, Pryor D, Rafferty GF: Assessment of respiratory drive and muscle function in the pediatric intensive care unit and prediction of extubation failure. Pediatr Crit Care Med 2000;1:124-126.

118 Coates AL, Stocks J, Gerhardt T: Esophageal manometry; in Stocks J, Sly PD, Tepper RS, Morgan WJ (eds): Infant Respiratory Function Testing. New York, Wiley, 1996 , pp 241-258.

119 Gappa M, Colin AA, Goetz I, Stocks J: Passive respiratory mechanics: The occlusion techniques. Eur Respir J 2001;17: 141-148.

120 Gappa M, Jackson EA, Pilgrim L, Costeloe $\mathrm{KC}$, Stocks J: A new microtransducer catheter for measuring esophageal pressure in infants. Pediatr Pulmonol 1996;22:117-124.

121 Katz-Salamon M: Delayed chemoreceptor responses in infants with apnoea. Arch Dis Child 2004;89:261-266.

122 Galland BC, Taylor BJ, Bolton DP, Sayers RM: Respiratory responses to hypoxia/hypercapnia in small for gestational age infants influenced by maternal smoking. Arch Dis Child Fetal Neonatal Ed 2003;88:F217-F222.

123 Schulze A, Abubakar K, Gill G, Way RC, Sinclair JC: Pulmonary oxygen consumption: A hypothesis to explain the increase in oxygen consumption of low birth weigh infants with lung disease. Intensive Care Med 2001;27:1636-1642.

124 Thach B: Fast breaths, slow breaths, small breaths, big breaths: Importance of vagal innervation in the newborn lung. J Appl Physiol 2001;91:2298-2300.

125 Tirosh E, Bilker A, Bader D, Cohen A: Capnography in spontaneously breathing preterm and term infants. Clin Physiol 2001;21:150-154

126 Williams O, Bhat RY, Cheeseman P, Rafferty GF, Hannam S, Greenough A: Exhaled nitric oxide in chronically ventilated preterm infants. Arch Dis Child Fetal Neonatal Ed 2004;89:F88-F89.

127 Franklin PJ, Turner SW, Mutch RC, Stick SM: Measuring exhaled nitric oxide in infants during tidal breathing: Methodological issues. Pediatr Pulmonol 2004;37:24-30.

128 Leipala JA, Williams O, Sreekumar S, Cheeseman P, Rafferty GF, Hannam S, Milner A, Greenough A: Exhaled nitric oxide levels in infants with chronic lung disease. Eur J Pediatr, in press

129 Bates J, Schmalisch G, Filbrun D, Stocks J: Tidal breath analysis for infant pulmonary function testing. Eur Respir J 2000;16: 1180-1192.

130 Stocks J, Dezateux CA, Jackson EA, Hoo A-F, Costeloe KL, Wade AM: Analysis of tidal breathing parameters in infancy. How variable is tPTEF:tE. Am J Respir Crit Care Med 1994; $150: 1347-1354$

131 Aston H, Clarke J, Silverman M: Are tidal breathing indices useful in infant bronchial challenge tests? Pediatr Pulmonol 1994;17: 225-230. 
132 Mikkilineni S, England S: On tidal expiratory flow measurements in infants. Pediatr Pulmonol 1994;18:71-72.

133 Rusconi F, Gagliardi L, Aston H, Silverman M: Changes in respiratory rate affect tidal expiratory flow indices in infants with airway obstruction. Pediatr Pulmonol 1996; 21:236-240.

134 Seddon PC, Davis GM, Coates AL: Do tidal expiratory flow patterns reflect lung mechanics in infants. Am J Respir Crit Care Med 1996;153:1248-1252.

135 Suki B: Fluctuations and power laws in pulmonary physiology. Am J Respir Crit Care Med 2002;166:133-137.

136 Frey U, Silverman M, Suki B: Analysis of the harmonic content of the tidal flow waveforms in infants. J Appl Physiol 2001;91:1687-1693.

137 Habib RH, Pyon KH, Courtney SE, Aghai $\mathrm{ZH}$ : Spectral characteristics of airway opening and chest wall tidal flows in spontaneously breathing preterm infants. J Appl Physiol 2003;94:1933-1940.

138 Schmalisch G, Foitzik B, Wauer RR, Stocks J: Effect of apparatus deadspace on tidal breathing parameters in newborns: Comparison of the 'flow-through' and conventional techniques. Eur Respir J 2000;17:108-114.

139 Schmalisch G, Schmidt M, Foitzik B: Novel technique to average breathing loops for infant respiratory function testing. Med Biol Eng Comput 2001;39: 688-693.

140 Brown K, Aun C, Jackson EA, Mackersie AM, Hatch DJ, Stocks J: Validation of respiratory inductive plethysmography using the qualitative diagnostic calibration method in anaesthetized infants. Eur Respir J 1998;12: 935-943.
141 Jackson EA, Stocks J, Pilgrim L, Dundas I, Dezateux CA: A critical assessment of uncalibrated respiratory inductance plethysmography for the measurement of tidal breathing parameters in newborns and infants. Pediatr Pulmonol 1995;20:119-124.

142 Colin AA: Infant pulmonary testing Techniques, physiological perspectives and clinical applications. Paediatr Respir Rev 2004;5(suppl 1):S73-S76.

143 Davis SD: Neonatal and pediatric respiratory diagnostics. Respir Care 2003;48:367-384.

144 Godfrey S, Bar-Yishay E, Avital A, Springer C: What is the role of tests of lung function in the management of infants with lung disease? Pediatr Pulmonol 2003;36:1-9.

145 Hanrahan J, Silverman M, Tepper R: Clinical epidemiology and future directions; in Stocks J, Sly PD, Tepper RS, Morgan WJ (eds): Infant Respiratory Function Testing. New York, Wiley, 1996, pp 551-562.

146 Castile RG: Pulmonary function testing in children; in Chernick V, Boat TF, Kendig EL (eds): Kendig's Disorders of the Respiratory Tract in Children. Philadelphia, Saunders, 1998, pp 196-214

147 Stocks J, Quanjer PH: Reference values for residual volume, functional residual capacity and total lung capacity. Eur Respir J 1995;8: 492-506.

148 Hulskamp G, Hoo AF, Ljungberg H, Lum S, Pillow JJ, Stocks J: Progressive decline in plethysmographic lung volumes in infants: Physiology or technology? Am J Respir Crit Care Med 2003;168:1003-1009.

149 Merkus PJ, Tiddens HA, de Jongste JC: Annual lung function changes in young patients with chronic lung disease. Eur Respir J 2002;19:886-891.
150 Subbarao P, Lebecque P, Corey M, Coates AL: Comparison of spirometric reference values. Pediatr Pulmonol 2004;37:515-522.

151 Aurora P, Stocks J, Oliver C, Saunders C, Castle R, Chaziparasidis G, Bush A; London Cystic Fibrosis Collaboration: Quality control for spirometry in preschool children with and without lung disease. Am J Respir Crit Care Med 2004;169:1152-1159.

152 Nielsen KG, Bisgaard H: Discriminative capacity of bronchodilator response measured with three different lung function techniques in asthmatic and healthy children aged 2 to 5 years. Am J Respir Crit Care Med 2001;164:554-559.

153 Nielsen KG, Pressler T, Klug B, Koch C, Bisgaard $\mathrm{H}$ : Serial lung function and responsiveness in cystic fibrosis during early childhood. Am J Respir Crit Care Med 2004 169:1209-1216.

154 ATS-ERS consensus statement, Sly P, Beydon N, Davies S, Gaultier C, Lombardi E, et al: Lung function testing in preschool children: The next frontier. Am J Respir Crit Care Med, in press.

Janet Stocks, $\mathrm{PhD}$

Professor of Respiratory Physiology

Portex Anaesthesia, Intensive Therapy and

Respiratory Medicine Unit

Institute of Child Health

30 Guilford St, London, WC1N 1EH (UK)

Tel. +44 2079052382

Fax +44207829 8634

E-Mail j.stocks@ich.ucl.ac.uk 
